\title{
Calculating Workplace WBGT from Meteorological Data: A Tool for Climate Change Assessment
}

\author{
Bruno LEMKE ${ }^{1 *}$ and Tord KJELLSTROM ${ }^{2,3}$ \\ ${ }^{1}$ School of Health, Nelson Marlborough Institute of Technology, New Zealand \\ ${ }^{2}$ National Centre for Epidemiology and Population Health, Australian National University, Australia \\ ${ }^{3}$ Centre for Global Health Research, Umea University, Sweden
}

Received November 25, 2011 and accepted May 7, 2012

Published online in J-STAGE May 30, 2012

\begin{abstract}
The WBGT heat stress index has been well tested under a variety of climatic conditions and quantitative links have been established between WBGT and the work-rest cycles needed to prevent heat stress effects at the workplace. While there are more specific methods based on individual physiological measurements to determine heat strain in an individual worker, the WBGT index is used in international and national standards to specify workplace heat stress risks. In order to assess time trends of occupational heat exposure at population level, weather station records or climate modelling are the most widely available data sources. The prescribed method to measure WBGT requires special equipment which is not used at weather stations. We compared published methods to calculate outdoor and indoor WBGT from standard climate data, such as air temperature, dew point temperature, wind speed and solar radiation. Specific criteria for recommending a method were developed and original measurements were used to evaluate the different methods. We recommend the method of Liljegren et al. (2008) for calculating outdoor WBGT and the method by Bernard et al. (1999) for indoor WBGT when estimating climate change impacts on occupational heat stress at a population level.
\end{abstract}

Key words: Heat stress, WBGT, Workplace, Weather data, Indoor, Outdoor, Climate change

\section{Introduction}

Measuring the effects of heat exposure in occupational health has many perspectives: for instance, the effect of heat on individuals undertaking a particular activity; or the effect of heat on a population of workers in a particular region; or the effect of increasing heat exposure due to climate change on the working population in different regions. Measurement of heat effects fall into two categories: heat stress and heat strain. Conventional engineering

*To whom correspondence should be addressed.

E-mail: bruno.lemke@nmit.ac.nz

(C)2012 National Institute of Occupational Safety and Health terminology defines stress as external forces and strain as the response by the object or individual to those stresses.

In this paper we focus on heat stress for which numerous indexes have been defined ${ }^{1}$. We will use WBGT (Wet Bulb Globe Temperature) because that is a wellestablished heat index for workplace applications with recommended rest/work cycles at different metabolic rates clearly specified in an international standard ${ }^{2}$.

New heat stress indexes such as the UTCI (Universal Thermal Climate Index) are based on the heat balance mechanisms of the human body ${ }^{3}$, and although they are based on the best physiological models of the body's response to heat, they are not as practical as the WBGT index. For example they do not take into account differences in metabolic rates during work, or the impact of special- 
Table 1. Often used abbreviations (all units in ${ }^{\circ} \mathrm{C}$ unless otherwise shown)

\begin{tabular}{llll}
\hline WBGTid & Indoor Wet bulb globe temperature & $\mathrm{Td}$ & Dew point temperature \\
WBGTod & Outdoor Wet bulb globe temperature & $\mathrm{Pa}$ & Atmospheric pressure $(\mathrm{hPa})$ \\
$\mathrm{Ta}$ & Air temperature & $\rho$ & Water vapour pressure $(\mathrm{hPa})$ \\
Tnwb & Natural wet bulb temperature & $\mathrm{SR}$ & Solar Radiation $\left(\mathrm{w} / \mathrm{m}^{2}\right)$ \\
Tpwb & Psychrometric wet bulb temperature & $\mathrm{v}$ & Wind speed $(\mathrm{m} / \mathrm{s})$ \\
$\mathrm{Tg}$ & Black globe temperature & & \\
\hline
\end{tabular}

ized protective clothing, or the constant change in position and movement during real work situations.

If individual heat strain data is required then physiological models exist to calculate heat strain. These include the required sweat rate model ${ }^{4)}$, the Predicted Heat Strain (PHS) Model $^{5)}$, the USAF model ${ }^{6)}$ and the Fiala model ${ }^{7)}$ to name a few.

The core body temperature of all humans is maintained close to $37^{\circ} \mathrm{C}$. The main mechanism of internal heat gain is the heat generated by muscles that work at approximately $20 \%$ efficiency ${ }^{8}$. Heat can be transferred to/from the body by convection, conduction, radiation and evaporation of water (sweat). Environmental factors that influence these heat transfer mechanisms, and the resulting heat stress, are air temperature, wind speed, humidity and heat radiation sources $^{8)}$. The heat stress is also dependent on the clothing and the intensity of muscular work (the metabolic rate) of the person ${ }^{8)}$.

Geographic variations of personal factors can be specified by a heat exposure standard that can vary from country to country. Such standards translate the WBGT index to a health risk function for the population ${ }^{9,10)}$. Indeed, the heat stress standard is different in cooler countries (e.g. England) than in hot countries (e.g. India) where the population is more acclimatized and better adapted to higher temperatures.

Increased heat exposure raises the core body temperature of the human body. While some increase in core temperature above $37^{\circ} \mathrm{C}$ is acceptable, an increase beyond $39^{\circ} \mathrm{C}$ creates health risks ${ }^{8)}$, which vary from person to person, depending on ethnic group, age, gender, the duration of high heat exposure, and the degree of acclimatization ${ }^{11)}$.

The International Standard for heat stress uses WBGT to recommend work-rest limits for work in hot environments ${ }^{2)}$ in order to ensure that average core body temperatures of worker populations does not exceed $38^{\circ} \mathrm{C}$. Many countries have national standards based on this international standard for WBGT limit values ${ }^{9)}$.

The WBGT index was developed after detailed studies by US military ergonomists in the $1950 \mathrm{~s}^{12,13)}$. While
WBGT has its critics ${ }^{14-16)}$, it has all the correct components to indicate physiological heat stress ${ }^{8)}$. One criticism of $\mathrm{WBGT}^{17,18)}$ is that it is too stringent for determining conditions when full work load should be reduced. This criticism has less to do with the WBGT index than the ISO standard criteria for reduction of the work $\operatorname{load}^{2}$. For instance, Nag et al. ${ }^{17)}$ considered that an increase in core body temperature up to $39^{\circ} \mathrm{C}$ was acceptable, while ISO limits the increase to $38^{\circ} \mathrm{C}$. The international standard is currently being updated by ISO ${ }^{19)}$ to address some of these criticisms and to update the scientific source materials.

A major disadvantage of WBGT is that, until recently, it could not be easily calculated from standard meteorological data. In this paper we review, assess and compare different published methods to calculate WBGT from readily available meteorological data, namely temperature, humidity, wind speed and solar radiation. Our main objective is to identify and develop a valid global method to calculate current and future heat stress using weather station data, and provide improved estimates of climate change related variations in occupational heat stress.

\section{Components in Calculations of WBGT}

The heat exposure index WBGT (unit $={ }^{\circ} \mathrm{C}$ ) is a combination of the natural wet bulb temperature (Tnwb, measured with a wetted thermometer exposed to the wind and heat radiation at the site), the black globe temperature ( $\mathrm{Tg}$, measured inside a $150 \mathrm{~mm}$ diameter black globe), and the air temperature (Ta, measured with a "normal" thermometer shaded from direct heat radiation). Table 1 presents a summary of variables discussed in this article.

Equation 1 ${ }^{8)}$ : outdoors (in conditions of direct short wave radiation): $\mathrm{WBGTod}=0.7 \mathrm{Tnwb}+0.2 \mathrm{Tg}+0.1 \mathrm{Ta}$

Equation 2 ${ }^{8)}$ : indoors or outdoors in the shade (no direct short wave radiation): $\mathrm{WBGTid}=0.7 \mathrm{Tnwb}+0.3 \mathrm{Tg}$

These simple equations were developed more than $50 \mathrm{yr}$ $\mathrm{ago}^{12)}$ and are still in use ${ }^{2)}$. The wet bulb thermometer simulates the cooling of the body via sweat evapora- 
tion, which is strongly related to air humidity. The globe thermometer simulates the heat absorption from radiation (from the sun or heat sources in the workplace). The temperatures recorded by these two thermometers are also modified by the air temperature (Ta) and the air movement (wind speed) around them.

\section{Different wet bulb temperatures}

The natural wet bulb temperature (Tnwb) is the largest component (70\%) of WBGT (see Equations 1 and 2). There are three versions of the "wet bulb temperature".

1. The Natural Wet Bulb temperature (Tnwb) is the temperature of a wetted thermometer bulb in the natural environment of wind and sun. Tnwb is a combination of air temperature and humidity but it is also influenced by heat radiation and wind speed.

2. The Wet Bulb temperature (Twb) used at some weather stations is the wetted bulb left in natural wind conditions but shielded from direct sunlight (ie in the shade).

3. The psychrometric or thermodynamic wet bulb temperature (Tpwb) is used to calculate dew point and relative humidity. Here the wetted bulb is in the shade and aspirated with a wind of 3-5 m/s created by a fan or by rotating a wetted thermometer ${ }^{20,21)}$.

Modern meteorological data is usually based on the psychrometric wet bulb temperature (Tpwb) which is linked to the dew point $(\mathrm{Td})$ by the formula:

Equation $3^{22)}: T d=243.5 \ln (\rho / 6.112) /(17.67-\ln (\rho / 6.112))$

where $\rho$ is the water vapor pressure in air (hecto-Pascals) calculated with equation 4 :

Equation $4^{22)}: \rho=6.112 \exp (17.67 \mathrm{Tpwb} /(\mathrm{Tpwb}+243.5))-$ 0.00066Patm(Ta-Tpwb)(1+0.00115Tpwb)

where Patm is the atmospheric pressure in hecto-Pascals (hPa).

Low cost WBGT meters that use electronic components to measure relative humidity rather than a wetted wick display the psychrometric wet bulb temperature rather than the natural wet bulb temperature. For wind speeds above 3 $\mathrm{m} / \mathrm{s}$, it matters little which wet bulb temperature is used ${ }^{23)}$. Measurements made at low wind speed, resulted in the natural wet bulb temperature being up to $1.5^{\circ} \mathrm{C}$ higher than the psychrometric wet bulb temperature indoors and nearly $10^{\circ} \mathrm{C}$ higher outdoors in the sun.

\section{Globe temperature $\mathrm{Tg}$}

The globe temperature ( $\mathrm{Tg}$ ) is a combination of short wave heat radiation (outdoors usually from the sun), long wave radiation (outdoors usually from the soil), and convective cooling due to wind on the thermometer. It contributes $20-30 \%$ of the WBGT (Equations 1 and 2 ). While Tnwb is the largest component in the WBGT formula (70\%), the $\mathrm{Tg}$ can be up to three times higher than Tnwb, so on balance both components can have a similar influence on WBGT.

Low wind speeds have a considerable effect on $\mathrm{Tg}$. The heat gained by the globe from radiation is essentially only lost by wind convection to cooler air around the globe. If there is no wind then the temperature rise by a stationary black globe left in the sun can be considerable. However, humans rarely stand still when they are working outdoors. Body movement generates air flow over the skin so the "wind speed" on the skin will never be 0 (as for a stationary WBGT monitor). In our calculations we use a standard wind speed at $1 \mathrm{~m} / \mathrm{s}$, so for windless conditions our calculated results will produce a more accurate WBGT for a moving worker than measured by a stationary WBGT meter. A standard wind speed of $1 \mathrm{~m} / \mathrm{s}$ was chosen because for actively working people, limb and torso movement would create an apparent wind speed greater than this. While WBGT shows a large dependence on wind speed when the wind speed is low, once the wind speed is over $1 \mathrm{~m} / \mathrm{s}$ there is only a minor increase in WBGT. For example, for an increase in wind speed from $1 \mathrm{~m} / \mathrm{s}$ to $5 \mathrm{~m} / \mathrm{s}$ there is at most a $5 \%$ increase in WBGT.

The original WBGT meter with a $150 \mathrm{~mm}$ diameter black globe takes approximately 20 min to reach equilibrium ${ }^{24)}$, so modern WBGT meters often use a smaller $50 \mathrm{~mm}$ diameter black globe. The $50 \mathrm{~mm}$ globe of the Quest Technology instrument reaches equilibrium in 10 min. Our calculations based on the "best" formula (see later) showed that the smaller globe underestimates Tg by less than $7 \%$ for $1 \mathrm{~m} / \mathrm{s}$ wind speed and in direct sunlight. Manufacturers of the smaller globes state that this has been corrected in their WBGT readings ${ }^{25)}$.

\section{Criteria for Establishing a Valid WBGT Calculation from Meteorological Data}

Our criteria to determine the best methods and formulas for calculating WBGT from meteorological data:

* The formula should only include well established meteorological variables related to temperature, humidity, wind speed and solar radiation to calculate both Tnwb and Tg as required by the WBGT formula (see equations 1 and 2).

* The method in deriving the formula should be based 
on sound thermodynamic principles of heat exchange between the environment and the black globe and the wetted wick. Empirical values of constants may be included in the formula.

* The formula should cover all common conditions encountered in the outdoors (for WBGTod) or indoors (for WBGTid).

* The formula should be easy to use.

* The formula should have been well tested with experimental data.

A number of authors have calculated WBGT from standard meteorological data: Dernedde and Gilbert ${ }^{26)}$ (1991), Bernard and Pourmoghani ${ }^{27)}$ (1999), Hunter and Minyard ${ }^{28)}$ (1999), ABM ${ }^{29)}$ (Australian Bureau of Meteorology), Tonouchi et al. ${ }^{30)}$ (2006), Liljegren et al. ${ }^{31)}$ (2008), Gaspar and Quintela ${ }^{32)}$ (2009). The methods are described below and will be referred to using the first author's name.

\section{Published Methods for Calculating WBGT and its Components}

\section{Dernedde and Bernard}

Dernedde and Gilbert ${ }^{26)}$ developed Tnwb temperature formulas based on the heat exchange of a wetted wick in the sun and wind. Bernard and Pourmoghani ${ }^{27)}$ developed this further resulting in the following equation where the first term is the convective heat exchange, the second term is the heat gained from radiation sources and the third term is the heat lost by evaporation:

Equation 5 $5^{26,27)}$ : $\mathrm{h}($ Ta-Tnwb $)+\varepsilon_{\mathrm{w}}\left(\mathrm{SR}-\sigma(\mathrm{Tnwb})^{4}\right)-\mathrm{kQ}(\mathrm{Ps}-$ $\mathrm{Pw}) /(\mathrm{Pa}-\mathrm{Pw})=0$

Variables and constants: $\mathrm{h}$ is the heat transfer of convection, $\varepsilon_{\mathrm{W}}$ is the emissivity of the wick, $\sigma$ is the StefanBoltzmann constant, $\mathrm{k}$ is the mass transfer coefficient of the wick, SR is solar radiation in $\mathrm{W} / \mathrm{m}^{2}$, Q is the latent heat of vaporization and Ps is the saturated partial pressure at the wick temperature. $\mathrm{Pw}$ is the partial pressure of water in the air and Patm is the atmospheric pressure. Ta and Tnwb were defined in Equation 1.

Bernard et al. ${ }^{27)}$ and Bernard ${ }^{23)}$ use the principles of heat exchange of a wetted wick with the environment and actual measurements to derive a semi-empirical formula for Tnwb for common summertime environmental conditions in the USA:

\section{Equation $6^{27)}$ :}

a) When $\mathrm{Tg}$ is $4{ }^{\circ} \mathrm{C}$ higher than Ta; Tnwb $=\mathrm{Tpwb}+0.25(\mathrm{Tg}$ $-\mathrm{Ta})+0.1 / \mathrm{v}^{1.1}-0.2$ b) When $\mathrm{Tg}-\mathrm{Ta}$ is $<4{ }^{\circ} \mathrm{C}$, and wind speed $\mathrm{v}$ is $>3 \mathrm{~m} / \mathrm{s}$, Tnwb $=$ Tpwb

c) Otherwise $\mathrm{Tnwb}=\mathrm{Ta}-\left(0.96+0.069 \log _{10} \mathrm{v}\right)(\mathrm{Ta}-\mathrm{Tpwb})$

Unfortunately Bernard's method does not include estimation of the black globe temperature in the sun. Their theory and measurements all apply to indoor environments without a solar radiation (SR) component. Hence this method is not suitable for outdoor WBGT, but it would be appropriate for indoor WBGT calculations.

For indoor conditions with no strong radiation sources, the approximation that $\mathrm{Tg}=\mathrm{Ta}$ was tested by us in the course of indoor WBGT measurements and agreed to within $0.5^{\circ} \mathrm{C}$. So using this approximation with the indoor WBGT formula (Equation 2) along with Bernard's Tnwb formula (Equation 6) we obtain:

Equation 7: $\mathrm{WBGTid}=0.7 \mathrm{Tpwb}+0.3 \mathrm{Ta}$

$$
(\mathrm{v}>3 \mathrm{~m} / \mathrm{s} ; \text { Tnwb }=\text { Tpwb; Tg }=\mathrm{Ta})
$$

WBGTid $=0.67 \mathrm{Tpwb}+0.33 \mathrm{Ta}-0.048 \log _{10} \mathrm{v}(\mathrm{Ta}-\mathrm{Tpwb})$ $(\mathrm{v}=0.3-3 \mathrm{~m} / \mathrm{s})$

Wind speeds less than $0.3 \mathrm{~m} / \mathrm{s}$ are not included in this analysis because a working person is unlikely to be completely stationary so an apparent wind speed of at least 1 $\mathrm{m} / \mathrm{s}$ (slow walk) will be generated. When the wind speed is $1 \mathrm{~m} / \mathrm{s}$ equation 7 reduces to:

\section{Equation 8: $\mathrm{WBGTid}=0.67 \mathrm{Tpwb}+0.33 \mathrm{Ta}$}

Comparing equation 8 with equation 7 when the wind speed is greater than $3 \mathrm{~m} / \mathrm{s}$, it can be seen that even for higher wind speeds the WBGTid reduces by only about than $6 \%$ of the $1 \mathrm{~m} / \mathrm{s}$ value.

Tpwb is calculated from air temperature (Ta) and dew point temperature $(\mathrm{Td})$ by iteration using a formula derived from $\mathrm{McPherson}^{33)}$ :

Equation 933): $1556 \mathrm{e}_{\mathrm{d}}-1.484 \mathrm{e}_{\mathrm{d}} \mathrm{Tpwb}-1556 \mathrm{e}_{\mathrm{w}}+1.484 \mathrm{e}_{\mathrm{w}}$ $\mathrm{Tpwb}+1010(\mathrm{Ta}-\mathrm{Tpwb})=0$

where $e_{d}=6.106 \exp (17.27 \mathrm{Td} /(237.3+\mathrm{Td}))($ in $\mathrm{hPa})$ and $\mathrm{e}_{\mathrm{w}}=6.106 \exp (17.27 \mathrm{Tpwb} /(237.3+\mathrm{Tpwb}))$ (in $\left.\mathrm{hPa}\right)$

\section{Hunter}

Hunter ${ }^{28)}$ used the principles of heat exchange to estimate globe temperature ( $\mathrm{Tg}$ ) by iteration of this formula:

Equation 10 ${ }^{29)}$ : $\left(1-\alpha_{\mathrm{gs}}\right) \operatorname{SR}\left(\mathrm{f}_{\text {dir }} /(4 \cos (\mathrm{z}))+\left(1+\alpha_{\mathrm{s}}\right) \mathrm{f}_{\mathrm{dif}}\right)+\varepsilon_{\mathrm{a}}(1-$ $\left.\alpha_{\mathrm{gl}}\right) \sigma \mathrm{Ta}^{4}=\varepsilon \sigma \mathrm{Tg}^{4}+13.28 \mathrm{v}^{0.58}(\mathrm{Tg}-\mathrm{Ta})$

The albedos $(\alpha)$ were assigned the following values: globe shortwave $\alpha_{\mathrm{gs}}=0.05$, globe long-wave $\alpha_{\mathrm{gl}}=0.05$, surrounds $\alpha_{\mathrm{s}}=0.2 \mathrm{z}$ is the zenith angle of the sun, $\mathrm{f}_{\mathrm{dir}}$ 
and $f_{\text {dif }}$ are the fractions of direct and diffuse radiation. $v$ is the wind speed in $\mathrm{m} / \mathrm{s}$ (hence the different coefficient before the $\mathrm{v}^{0.58}$ term from that in the formula in Hunter's paper $^{28)}$ ). $\sigma$ is the Stefan-Boltzmann constant. $\varepsilon_{\mathrm{a}}$ is the thermal emissivity of the air, and $\varepsilon$ is the thermal emissivity of the globe $=0.95$.

The two terms on the left of the equation represent the short wavelength and long wavelength radiation absorbed by the globe. The two terms on the right represent the radiation emitted by the globe and the energy lost by convection. The $13.28 \mathrm{v}^{0.58}$ is empirically derived ${ }^{34)}$ for the heat loss of the black globe from wind blowing over it.

To calculate Tnwb, Hunter ${ }^{28)}$ used an empirical formula derived for hot dry conditions in the USA (South Carolina). His formula (converted from degrees Fahrenheit to Celsius) is:

Equation 11 ${ }^{28)}$ : Tnwb $=$ Tpwb +0.0117 SR- $0.233 v+1.072$

where $\mathrm{v}$ is wind speed in $\mathrm{m} / \mathrm{s}$ and $\mathrm{SR}$ is solar radiation on the wick (in $\mathrm{W} / \mathrm{m}^{2}$ ) .

As the derivation of Tnwb (the main term in WBGT) is empirical, this fails to meet one of the criteria for establishing the best formula. However, we will compare the results of Hunter's method with other methods to calculate WBGT and comment on the closeness of fit of his formula.

\section{$A B M$}

The Australian Bureau of Meteorology (ABM) has published on its website ${ }^{29)}$ a simple formula for WBGT that requires as input only water vapour pressure $(\rho)$ and air temperature (Ta).

Equation 12 ${ }^{29)}$ : WBGT $\left({ }^{\circ} \mathrm{C}\right)=0.567 \mathrm{Ta}+0.393 \rho+3.94$

The website gives a standard physical science formula to calculate $\rho$ from RH (relative humidity) and Ta.

Equation 13 ${ }^{29)}: \rho(\mathrm{hPa})=\mathrm{RH} / 100 \times 6.105 \exp (17.27 \mathrm{Ta} /$ $(237.7+\mathrm{Ta}))$

While the ABM formula is easy to use, it proved difficult to establish the origin of the formula as the reference given $^{35)}$ does not have the formula. We tracked down the original reference to an empirical regression fit of WBGT vs temperature and humidity in a paper by Gagge and Nishi in $1976^{36)}$. Using their formula and converting to $\mathrm{hPa}$ their WBGT relation is

\section{Equation 14 ${ }^{36)}$ : WBGTid $=0.567 \mathrm{Ta}+0.216 \rho+3.38$}

This is different to the formula quoted on the ABM web- site. Further, this formula is empirically derived for indoor conditions and does not include the effects of solar radiation and wind speed.

Thus, the ABM formula does not match our criteria for validity. We include this formula in our comparisons because other authors have used this formula to estimate outdoor WBGT.

\section{Tonouchi}

Tonouchi $^{30)}$ calculated WBGT using the psychrometric wet bulb temperature (Tpwb) instead of Tnwb. For the solar component he used this empirically derived formula for Tg:

Equation 15 ${ }^{30)}: \operatorname{Tg}\left({ }^{\circ} \mathrm{C}\right)=\mathrm{Ta}+0.0175 \mathrm{SR}-0.208 \mathrm{v}$

The radiation component used by Tonouchi was the solar radiation incident on a flat horizontal plane instead of that on a sphere.

This rendered the Tonouchi method as unsuitable as it did not match our criteria in establishing a suitable formula. We will include this method in our comparisons as an example of recent formulas derived empirically at one location.

\section{Liljegren and Gaspar}

Liljegren et al. ${ }^{31)}$ and Gaspar and Quintela ${ }^{32)}$ used heat exchange principles to calculate Tnwb and Tg. For Tnwb they used a method similar to Bernard and for Tg they refined the Hunter formula to include effects of different amounts of radiation from the sky and the ground.

\section{Liljegren}

The Liljegren calculation for Tg includes both the direct and diffuse components of sunlight so their method is applicable for both sunny and cloudy conditions. Their formula is not simple, but they make available a computer $\operatorname{program}^{31)}$ to calculate WBGT outdoors. The Liljegren method meets all our criteria for outdoor WBGT calculations from meteorological data.

Liljegren's formula assumes that when there is no solar radiation the Tnwb equals Tpwb. As discussed earlier, the Tpwb is defined as the wet bulb temperature without sunlight exposure and a wind speed greater than $3 \mathrm{~m} / \mathrm{s}$. At lower wind speeds the air around the wet bulb saturates so preventing further evaporation (and hence further cooling) resulting in Tnwb readings higher than Tpwb. As indoor wind speeds are expected to be lower than $3 \mathrm{~m} / \mathrm{s}$, Liljegren's formula underestimates the Tnwb indoors. We therefore decided to use the Liljegren formula only for 


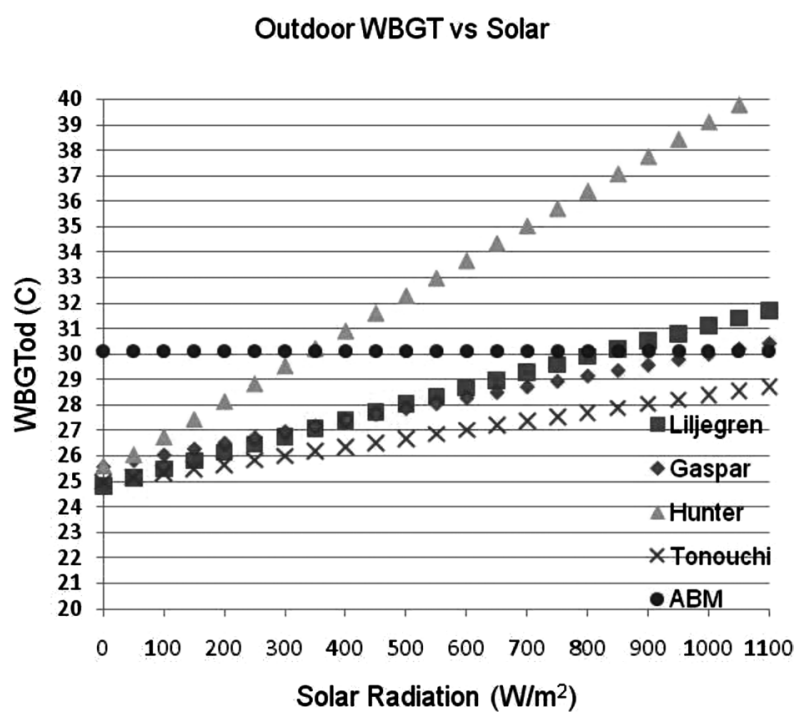

Fig. 1. The effect of solar radiation on calculated WBGT outdoors for various models.

Wind speed $=1 \mathrm{~m} / \mathrm{s}$, humidity $=55 \%$ and air temperature $=30^{\circ} \mathrm{C}$.

outdoor WBGT calculations.

\section{Gaspar}

The Gaspar ${ }^{32)}$ method requires the construction of extensive formulas and a computer program for iteration. This method is not easy to use. Further, the Gaspar Tg formula is only for clear skies and their measurements do not consider the effect of direct and diffuse radiation. As the high outdoor WBGT in tropical climates is often in humid overcast conditions the Gaspar Tg does not meet our criteria of covering all common meteorological conditions.

\section{Our comparative measurements}

For indoor WBGT measurements we used a certified WBGT meter (model QUESTemp 34 from Quest Technologies inc.). To measure the temperature and humidity required for an indoor WBGT calculation we used a number of different temperature probes (eg Fluke 80T-150) and humidity meters (eg UMP WS2015H). For outdoor measurements we used the same Quest meter for WBGT measurements. For humidity, wind speed, temperature and radiation values required for the outdoor WBGT calculations we used a certified Campbell CR10 weather station (see acknowledgements).

\section{Results and Discussion: Comparing WBGT Calculation Methods and Measurements}

The previous section discussed various methods for de-

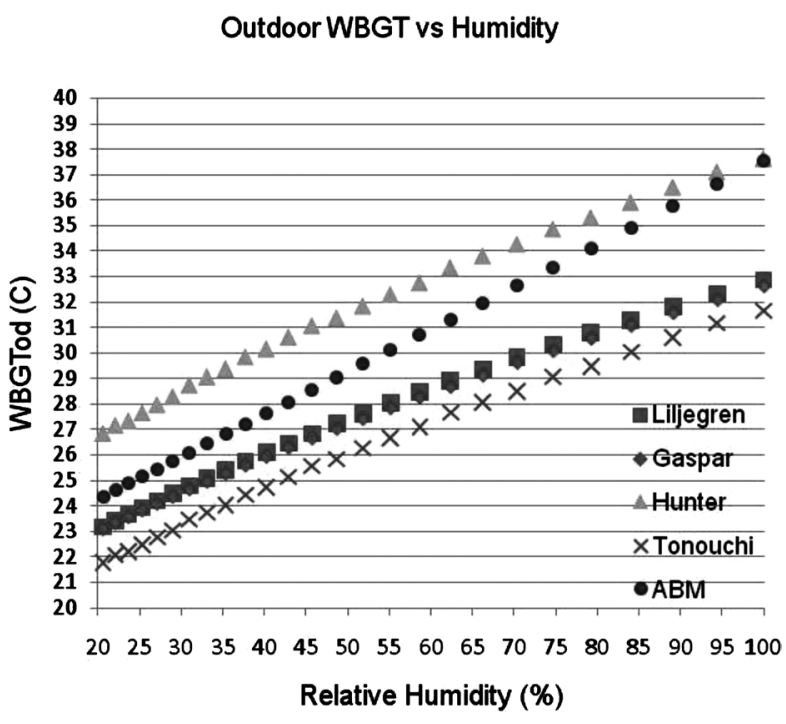

Fig. 2. The effect of humidity on calculated WBGT outdoors for various models.

Solar radiation $=500 \mathrm{~W} / \mathrm{m}^{2}$, wind speed $=1 \mathrm{~m} / \mathrm{s}$, air temperature $=30^{\circ} \mathrm{C}$.

riving WBGT from readily available meteorological variables. Two methods met our validity criteria: the method of Bernard for indoor WBGT and the method of Liljegren for outdoor WBGT. While the following data compares models, it should be noted that the various models have been compared with actual data by the researchers who developed the models. The Liljegren formula with $\mathrm{Tg}=$ Ta could have been used for the indoors, but the Bernard formula was a better fit to our criteria as it is much easier to use.

\section{Outdoor WBGT comparisons}

Figures 1 through 4 compare the calculated outdoor WBGTs using different methods for a range of climate variables. The method by Hunter does not agree well with the other methods. The empirical formula by Hunter ${ }^{28)}$ for Tnwb (Equation 11) is problematic because it consistently gives much higher Tnwb and WBGT values than the other methods. Indeed, for the solar radiation on the white wetted wick alone, Equation 11 adds $8^{\circ} \mathrm{C}$ to the WBGT for conditions of full sunlight. This is without including the solar radiation acting on the globe. While Hunter tested the accuracy of his formula, this was only on one day (early summer) when the conditions (cloud cover) might have been such that the calculations gave a good match with the WBGT measurements.

As shown in Figs. 1 to 4, the published ABM formula ${ }^{29)}$ also does not agree with the other results. In particular, the ABM formula does not vary with solar radiation nor wind 


\section{Outdoor WBGT vs Wind Speed}

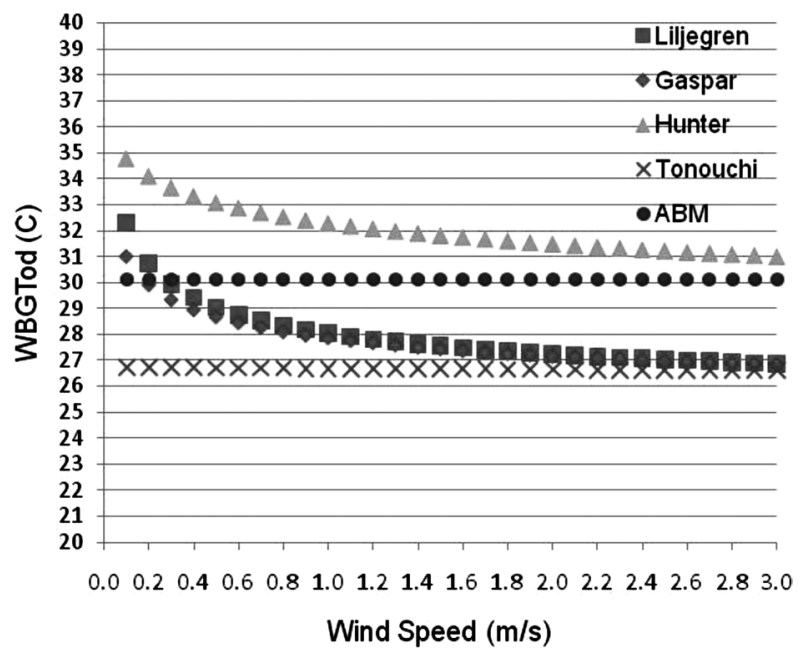

Fig. 3. The effect of wind speed on calculated WBGT outdoors for various models.

Solar radiation $=500 \mathrm{~W} / \mathrm{m}^{2}$, Humidity $=55 \%$ and air temperature $=30^{\circ} \mathrm{C}$.

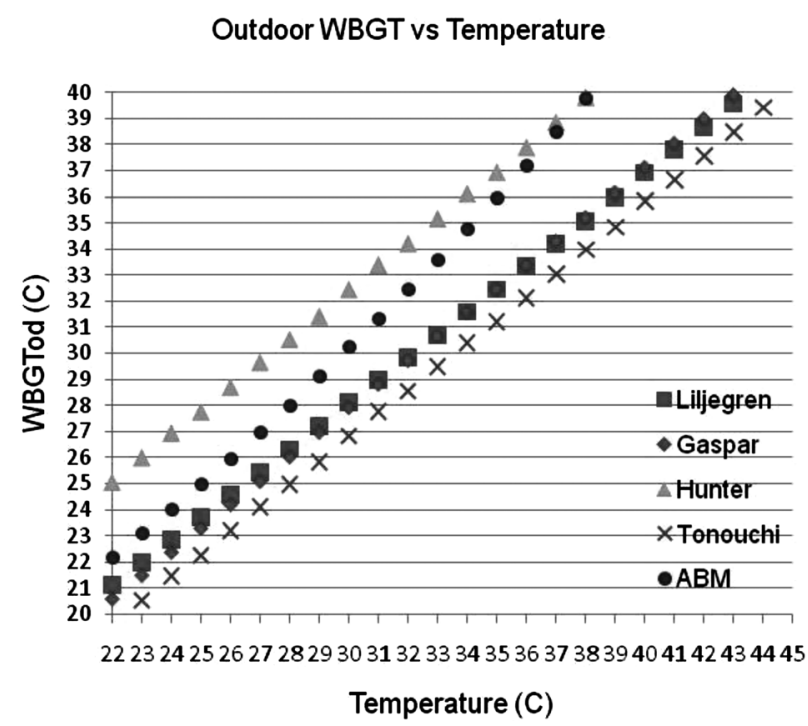

Fig. 4. The effect of temperature on calculated WBGT outdoors for various models.

Humidity $=55 \%$, Solar radiation $=500 \mathrm{~W} / \mathrm{m}^{2}$ and wind speed $=1 \mathrm{~m} / \mathrm{s}$. speed as Gagge and $\mathrm{Nishi}^{36)}$ derived their formula for indoor conditions that did not include those components.

The WBGT calculated via the Tonouchi formula ${ }^{30)}$ is close to, but lower than that of the other methods (Figs. 1 to 4). This is primarily because the Tonouchi formula uses Tpwb rather than Tnwb in the calculation of WBGT, which also explains why the influence of wind speed is much reduced in the Tonouchi calculation (Fig. 3).

Liljegren ${ }^{31)}$ made extensive comparisons between the calculated outdoor WBGT and measured WBGT and found that the difference between the two varied by less than $1{ }^{\circ} \mathrm{C}$ for $95 \%$ of the time, except in some locations where they attributed the difference to equipment problems.

Figures 1 to 4 show that the methods of Liljegren ${ }^{31)}$ and Gaspar $^{32)}$ are in good agreement. Gaspar reported a small but consistent overestimation in their calculations, which could be attributed to very low wind speeds that prevented accurate estimations of this parameter. The largest discrepancy between the results of Gaspar and Liljegren is in the solar data. This is not surprising as the method of Gaspar was only formulated for clear sky conditions.

\section{Field measurement comparisons outdoors}

Accurate comparisons of calculated WBGT with measured values is very difficult in real outdoor situations. Different equipment takes different times to reach equilibrium: for example, the WBGT black globe responds more slowly than a pyrometer to solar radiation. This coupled with changing cloud cover so that one piece of equipment reaches equilibrium while the other does not reach equilibrium makes direct comparisons difficult. Figure 5 shows the actual outdoor WBGT (Quest) and the calculated outdoor WBGT (Liljegren) over a period of 4 days in Nelson, New Zealand.

A difference of greater than $2^{\circ} \mathrm{C}$ can be seen at times. However, the largest difference between the measured and calculated values for all three days was between 11 a.m. and noon when the WBGT was rapidly increasing, and presumably equilibrium conditions were not reached. If the data between $11 \mathrm{a} . \mathrm{m}$. and noon is removed then the results comparing the measured and calculated outdoor WBGT have a correlation coefficient of $98 \%$.

The RMSE (root mean square error) between the measured and calculated WBGT is $0.95^{\circ} \mathrm{C}$. However the RMSE between the calculated WBGT using the weather station data and the calculated WBGT using the temperature and humidity data from the Quest equipment was slightly higher at $0.97^{\circ} \mathrm{C}$. Thus, differences in the temperature and humidity values between two nearby recorders resulted in about the same "error" as between the calculated and measured outdoor WBGT values.

\section{Indoor WBGT comparisons}

Indoor WBGT readings are far more reproducible than outdoor WBGT because the two major sources of varia- 


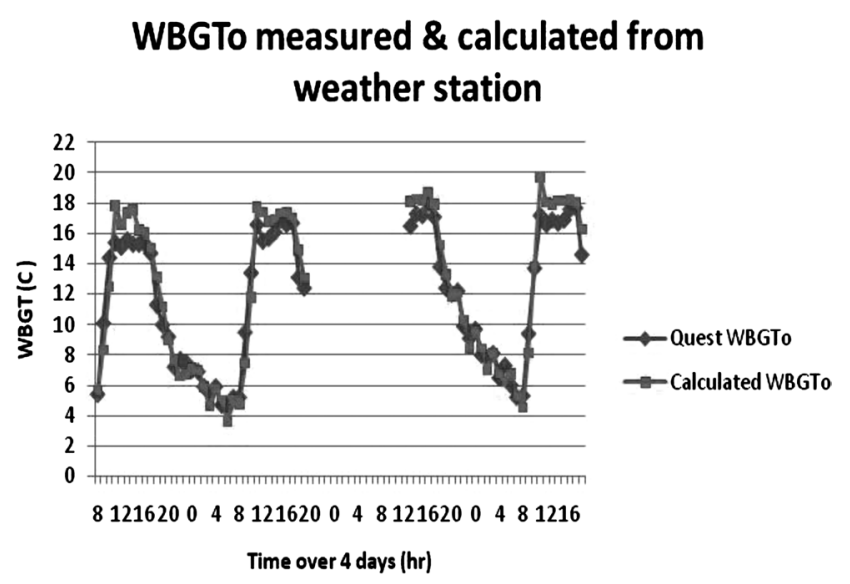

Fig. 5. Measured outdoor WBGT compared to calculated WBGT over $4 \mathrm{~d}$ in April 2010.

The data for the calculated values were taken from a nearby weather station. Location: near Nelson - north of the South Island of NZ.

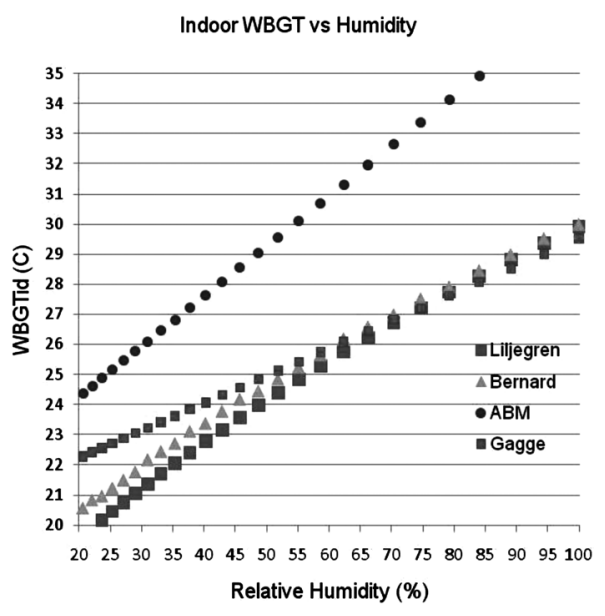

Fig. 6. Indoor WBGT calculations by Liljegren, $\mathrm{ABM}$ and Bernard.

Air temperature $=30^{\circ} \mathrm{C}$. Results for Gagge also included as a comparison with ABM.

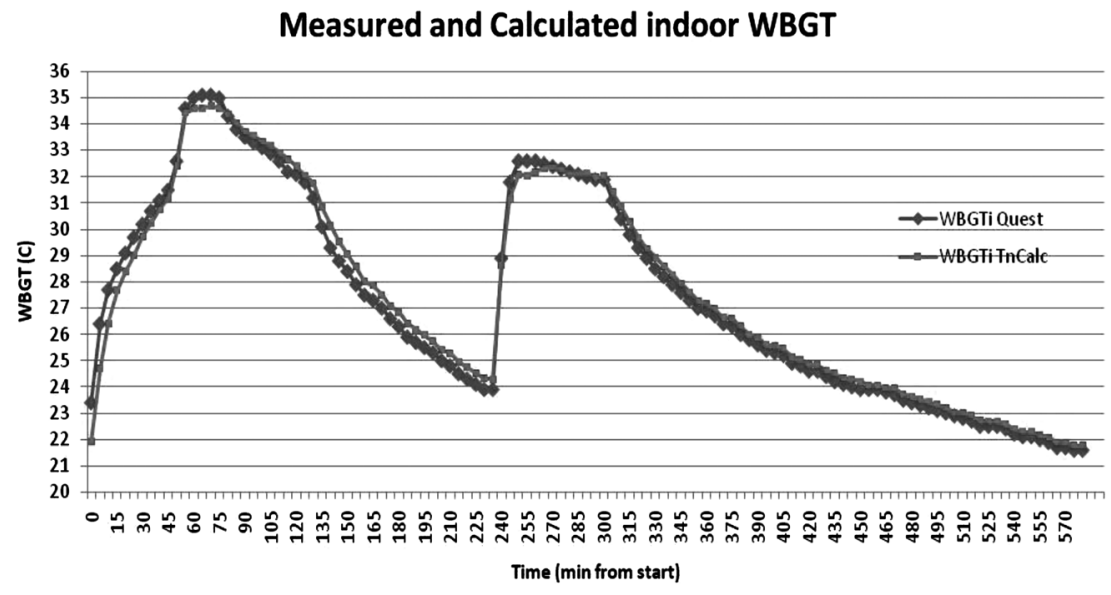

Fig. 7. Measured indoor WBGT compared to calculated indoor WBGT.

Data from climate chamber. Temperature varied from 20 to $40^{\circ} \mathrm{C}$, humidity varied from $30 \%$ to $90 \%$. Wind speed approximately $0.5 \mathrm{~m} / \mathrm{s}$.

tion, cloud cover and wind speed, are eliminated. In our calculations for the indoors, we assume there is some movement by the workers that generates an apparent wind speed of $1 \mathrm{~m} / \mathrm{s}$ (slow walk).

Bernard $^{27)}$ extensively compared calculated WBGT with indoor measurements and there is little point repeating these. While the other researchers, whose methods have been discussed in this paper have not carried out indoor measurements, it is useful to compare Bernard's results with that of Liljegren and $\mathrm{ABM}$ as the latter was originally derived for indoor conditions. Figure 6 shows this comparison. The ABM formula clearly gives an indoor WBGT that is much too high. For comparison the figure also shows results for a Gagge WBGT method (Equation 14) on which the ABM formula is based.

While the method of Bernard and Liljegren are close for indoor WBGT, it can be seen that the Liljegren results are about 5\% less than that using the Bernard method. Liljegren did not test their formula indoors while Bernard did extensive testing. This is one reason that we use the Bernard formula for indoor WBGT calculations.

\section{Comparison with our measurements}

Figure 7 shows a comparison between typical indoor WBGT measurements and WBGT calculations using Equation 8. The WBGT readings were using a Quest 


\section{WBGT indoors}

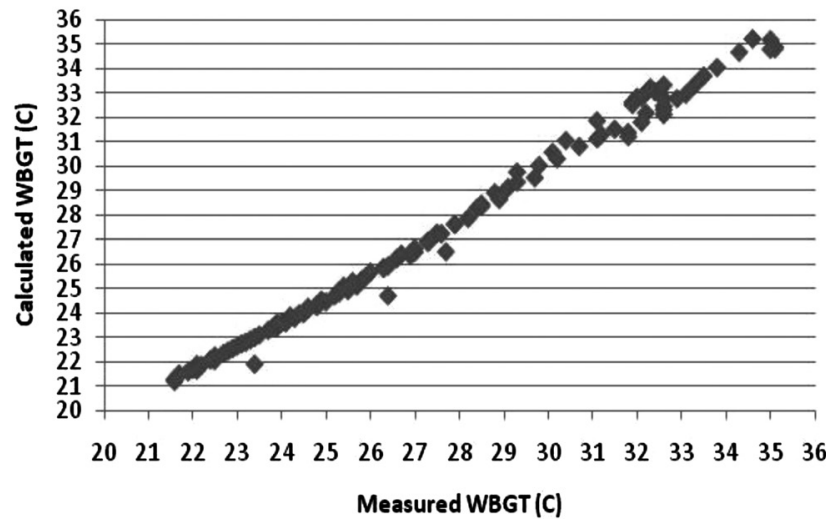

Fig. 8. Indoor WBGT calculations by Bernard compared to measured indoor WBGT values.

Same experimental conditions as for Fig. 7.

WBGT meter which also recorded the relative humidity and the air temperature, so it could be used to calculate WBGT from the Liljegren formula. Figure 8 shows that the agreement between theoretical and measured values is within $0.5^{\circ} \mathrm{C}$, except for a few points where it was identified that there was a rapid rise in humidity and the Tnwb had not reached equilibrium. The difference between the measured and calculated indoor WBGT has a RMSE $=$ $0.47^{\circ} \mathrm{C}$ for all points, and $\mathrm{RMSE}=0.40^{\circ} \mathrm{C}$ if the nonequilibrium points are removed.

\section{Overall Discussion and Conclusions}

A number of methods and calculation "models" have been proposed for calculating the WBGT from standard meteorological data. Some of these models are empirical (Tonouchi et al., ABM, Hunter, Bernard) and others are based on thermodynamic heat exchange principles (Dernedde and Gilbert, Liljegren et al., Gaspar and Quintela). It is clear from our analysis that some WBGT formulas derived from standard meteorological data are better than others. We found that the Australian Bureau of Meteorology formula quoted on their web site is incorrect. Research based on the ABM formula (e.g. Hancock et $\left.a l .{ }^{37)}\right)$ needs to be re-evaluated.

While there are differences between the calculated and measured WBGT using the "best models", much of this can be attributed to differences in the measurement of temperature and humidity rather than errors in the formula. It should be noted that WBGT measurements with special equipment also have measurement errors ${ }^{25}$. These include the fact that the standard $150 \mathrm{~mm}$ diameter black globe takes up to $20 \mathrm{~min}$ to reach equilibrium so scattered cloud will also cause errors. Non-standard $50 \mathrm{~mm}$ diameter globes reach equilibrium more quickly, but give a slightly smaller equilibrium temperature. Electronic wet bulb temperature equipment may be less expensive but Tpwb is measured rather than Tnwb. Good quality WBGT instruments are generally large and bulky which means they are kept stationary rather than moving with the individual.

Hardcastle and Butler ${ }^{25}$ ) have compared a number of commercial WBGT meters and found differences of between $1-2^{\circ} \mathrm{C}$ in their WBGT results. Hence the small difference between measured values and calculated WBGT using the Liljegren method is less than the reported variability of measurement results.

\section{Weather station and solar radiation data}

Typical weather stations record hourly (or more or less frequently) temperature, wind speed, and dew point. In addition, recordings are usually made of atmospheric pressure, rainfall, wind direction and visibility. Historical data going back decades or longer can be found from airports at most large cities of the world. We used a database including thousands of weather stations that is updated on a daily basis by the US National Climatic Data Centre at NOAA (National Oceanic and Atmospheric Administration, USA). Daily data (average, minimum, and maximum 24-h temperature; average wind speed; average humidity, usually in the form of dew point $\mathrm{Td}$; and some other variables) are available free from the NOAA web site ${ }^{38)}$ in the GSOD (Global Summary of the Day) files. Hourly data is available from the same web site or on CDs from NOAA at a modest cost (about US\$22 for 1 yr's global data). Unfortunately the NOAA data does not usually include solar radiation, which is required for the most accurate estimates of WBGT outdoors.

The best source of actual daily solar radiation is the satellite data from the NASA GEWEX site. This supplies the average daily direct solar radiation for a $100 \mathrm{~km} \times 100 \mathrm{~km}$ area for any latitude and longitude. The current database has data from 1983 to the present time. Useful data extracted from this site is the average daily short wave radiation (Average SR \{day\}) incident on that area of the globe and the maximum possible direct solar radiation (Max SR $\{$ day $\}$ ), if there were no clouds.

The daily solar radiation data from NASA can be converted to hourly SR data using a formula ${ }^{39)}$ available from the NOAA site ${ }^{40)}$ that permits the calculation of the maximum direct and diffuse solar radiation for clear skies 
for each hour of the day for any day in the year and for any latitude and longitude. This is the maximum solar radiation that can fall on an area per hour: Max SR \{hour\}.

The calculated hourly average solar radiation for a particular day is then given by:

Equation 19: Average SR $\{$ hour $\}=\operatorname{Max} \operatorname{SR}\{$ hour $\} \times$ Average SR \{day\} / Max SR dday\}

This hourly solar radiation has both the diffuse and the direct component of solar radiation attenuated by the same amount. In practice, this is incorrect as the clouds do not attenuate the diffuse radiation to anywhere the same extent as they attenuate the direct radiation. A better approximation is difficult to find as the proportion of direct and diffuse radiation is very dependent on the type of cloud. Zhang et al. ${ }^{41)}$ have used an empirical formula (including cloud cover) developed by Watanabe et $a l .{ }^{42)}$ for China and obtained good agreement with measurements.

It should be noted that for scattered clouds and rapidly varying levels of heat radiation, the WBGT meter cannot produce an accurate estimate of WBGT anyway as the globe takes up to $20 \mathrm{~min}$ to reach equilibrium.

\section{Future WBGT based on predicted climate change}

Future WBGT trends related to climate change will rely primarily on forecasted trends of daily temperature and humidity ${ }^{43)}$. Wind speeds are likely to change in less predictable ways. Solar radiation on clear days will be the same as now, but the future changes in cloud cover are difficult to forecast. For future outdoor WBGT predictions, certain assumptions about wind speed and cloud cover have to be made. The obvious assumption is that wind speed and cloud cover do not change. As WBGT indoors is not affected by solar radiation or wind speed then indoor WBGT trends can be estimated from future climate modeling trends in "indoors" locations where indoor temperature and humidity are the same as outdoors. This is a common situation in low income communities and countries where air conditioning is rare and windows are open or nonexistent. This applies to residential buildings as well as to workshops and factories where poor people work ${ }^{44)}$. This allows us to estimate a WBGT field change ${ }^{45)}$ using indoor data and then super-impose that field change on actual WBGT measurements for any location.

The ongoing climate change makes temporal and spatial variations of workplace heat exposure into key public health and occupational health issues in tropical and subtropical parts of the world. Our methods will improve the analysis of these variations at a local, regional and country level. New initiatives for occupational health management will be necessary to protect the health and productivity of working people ${ }^{46)}$.

Our methods do not allow for WBGT calculation at a specific work-place because workplace conditions can be significantly different from conditions at the nearby meteorological station. While WBGT meters are still best for specific workplace conditions we are currently using the methods outlined in this paper to enable us to calculate specific workplace WBGTs from data obtained from cheap data loggers that record only humidity and temperature.

We conclude that the Liljegren formula for WBGT outdoors gave the most valid results, because it is based on basic physics heat exchange formula and has been extensively tested in the outdoors. For WBGT indoors we concluded that the best is the Bernard formula with $\mathrm{Tg}=\mathrm{Ta}$ (assuming indoors with no local heat radiation source), because it has been well tested by Bernard and Pourmoghani.

These methods of calculating WBGT allow us to produce WBGT time trends going back to 1980 and beyond, and to incorporate climate change predictions for a location in order to estimate future WBGT values.

\section{Acknowledgements}

The authors declare that we have no commercial interests in different kinds of heat measurements and analysis or other conflicts of interest.

The research was supported by financial resources from the National Centre for Epidemiology and Population Health, Australian National University, Canberra, Australia. Some of these funds were from the Healthy Urban Systems project co-sponsored by CSIRO, Australia.

The authors thank Tony Hewitt of Envirolink Ltd (Mapua NZ) for access to local weather station data in Nelson.

\section{References}

1) d'Ambrosio Alfano FR, Palella BI, Riccio G (2011) Thermal environment assessment reliability using temperature - humidity indices. Ind Health 49, 95-106. [Medline] [CrossRef]

2) ISO (1989) Hot environments - Estimation of the heat stress on working man, based on the WBGT-index (wet bulb globe temperature). ISO Standard 7243. International Standards Organization, Geneva.

3) UTCI Universal Thermal Climate Index http://www.utci. org/. Accessed August 7, 2011.

4) ISO (1989) Hot environments - analytical determination 
and interpretation of thermal stress using calculation of required sweat rate. ISO Standard 7933. International Standards Organisation, Geneva.

5) Malchaire JBM (2006) Occupational heat stress assessment by predicted heat strain model. Ind Health 44, 380-7. [Medline] [CrossRef]

6) Yokota M, Berglund L (2006) Initial capability decision aid thermal prediction model and its validation. USARIEM Technical Report T06-03.

7) Fiala D, Lomas K, Stohrer M (2001) Computer predictions of human thermoregulatory and temperature responses to a wide range of environmental conditions. Int $\mathrm{J}$ Biomet 45, 143-59. [CrossRef]

8) Parsons K (2003) Human thermal environments. In: The effects of hot, moderate and cold temperatures on human health, comfort and performance. 2nd ed., Taylor \& Francis, London.

9) ILO (2001) Ambient factors in the workplace. International Labour Organization (ILO) codes of practice. International Labour Office, Geneva.

10) Parsons K (2006) Heat stress standard ISO 7243 and its global application. Ind Health 44, 368-79. [Medline] [CrossRef]

11) Wakabayashi H, Wijayanto T, Lee JY, Hashiguchi N, Saat M, Tochihara Y (2011) Comparison of heat dissipation response between Malaysian and Japanese males during exercise in humid heat stress. Int J Biometeorol 55, 509-17. [Medline] [CrossRef]

12) Yaglou CP, Minard D (1956) Prevention of heat casualties at marine corps training centres. Armed Services Technical Information Agency Document Service Center AD099920.

13) Stonehill RB, Keil PG (1961) Successful preventive medical measures against heat illness at Lackland Air Force Base. Am J Public Health Nations Health 51, 586-90. [Medline] [CrossRef]

14) Budd GM (2008) Wet-bulb globe temperature (WBGT)its history and its limitations. J Sci Med Sport 11, 20-32. [Medline] [CrossRef]

15) Brotherhood JR (2008) Heat stress and strain in exercise and sport. J Sci Med Sport 11, 6-19. [Medline] [CrossRef]

16) Brake R, Bates GP (2002) A valid method for comparing rational and empirical heat stress indices. Ann Occup Hyg 46, 165-74. [Medline] [CrossRef]

17) Park EK, Nag A, Ashtekar SP (2009) Thermal limits of men in moderate to heavy work in tropical farming. Ind Health 47, 200-1. [Medline] [CrossRef]

18) Brake DJ, Bates GP (2002) Limiting work rate (Thermal Work Limit) as an index of thermal stress. Appl Occup Environ Hyg 17, 176-86 (ACGIH). [Medline] [CrossRef]

19) Parsons K (2011) Personal communication at Lund expert panel meeting on International Guidelines on Indicators of Occupational Heat Hazards Lund, Sweden July 2011.

20) Finucane E (2006) Definitions, conversions and calculations for Occupational Safety and Health Professionals, 3rd Ed., Taylor and Francis, London.
21) Nakahama H (1999) Humidity measurement and psychrometers in environmental testing equipment. Environmental Testing Information: Technology Report No.7 http://www.espec.co.jp/english/tech-info/tech_info/. Accessed January 12, 2011.

22) Brice T, Hall T (2009) Wet-bulb calculator http://www.srh. noaa.gov/epz/?n=wxcalc. Accessed July 16, 2011.

23) Bernard TE (2005) Psychrometrics and useful relationships among heat stress measures. v1.0 http://www.health.usf. edu/ tbernard. Accessed March 30, 2011.

24) Juang YJ, Lin YC (2007) The effect of thermal factors on the measurement of wet globe temperature. J Occup Saf Health 15, 191-203.

25) Hardcastle S, Butler K (2008) A comparison of globe, wet and dry temperature and humidity measuring devices available for heat stress assessment. 12th US/North American Mine Ventilation Symposium, Wallace (Ed.).

26) Dernedde E, Gilbert D (1991) Prediction of wet-bulb globe temperatures in aluminium smelters. Am Ind Hyg Assoc J 52, 120-6. [CrossRef]

27) Bernard TE, Pourmoghani M (1999) Prediction of workplace wet bulb global temperature. Appl Occup Environ Hyg 14, 126-34. [Medline] [CrossRef]

28) Hunter C, Minyard O (1999) Estimating wet bulb globe temperature using standard meteorological measurements. Report WSRC-MS-99-00757. Westinghouse Savannah River Company, Aiken.

29) ABM (2009) About the WBGT and apparent temperature indices. Bureau of Meteorology, Commonwealth of Australia, Melbourne, Website. http://www.bom.gov.au/ info/thermal_stress/.Accessed June 3, 2011.

30) Tonouchi M, Murayama K, Ono M (2006) WBGT forecast for prevention of heat stroke in Japan. Sixth Symposium on the Urban Environment. AMS Forum: Managing our Physical and Natural Resources: Successes and Challenges JP1.1.

31) Liljegren JC, Carhart R, Lawday P, Tschopp S, Sharp R (2008) Modeling wet bulb globe temperature using standard meteorological measurements. J Occup Environ Hyg 5, 645-55. [Medline] [CrossRef]

32) Gaspar AR, Quintela D (2009) Physical modelling of globe and natural wet bulb temperatures to predict WBGT heat stress index in outdoor environments. Int J Biometeorol 53, 221-30. [Medline] [CrossRef]

33) McPherson MJ (2008) Subsurface Ventilation and Environmental Engineering, 2nd Ed., Chapter 17. Physiological reactions to climatic conditions. Mine Ventilation Services Inc., Clovis. http://www. mvsengineering.com/index.php?cPath=25.

34) Kuehn LA, Stubbs RA, Weaver RS (1970) Theory of the globe thermometer. J Appl Physiol 29, 750-7. [Medline]

35) ACSM (1984) Prevention of thermal injuries during distance running. American College of Sports Medicine, Position Stand. Med J Aust 141, 876-9. [Medline]

36) Gagge AP, Nishi Y (1976) Physical Indices of the thermal 
environment. ASHRAE J 18, 47-51.

37) Hancock PA, Ross JM, Szalma JL (2007) A meta-analysis of performance response under thermal stressors. Hum Factors 49, 851-77. [Medline] [CrossRef]

38) NOAA (2011) National Oceanic and Atmospheric Administration website. Global Summary of the day. http:// www.ncdc.noaa.gov/cgi-bin/res40.pl?page=gsod.html. Accessed August 23, 2011.

39) Bird RE, Hulstrom RL (1981) A simplified clear-sky model for the direct and diffuse insolation on horizontal surfaces. US-SERI Technical Report TR-642-761, Golden, Colorado.

40) Pelletier Greg (2002) solrad.xls (version 1.2) A solar position and radiation calculator for Microsoft Excel/VBA based on Bird and Hulstrom model. www.srrb.noaa.gov/ highlights/sunrise/azel.html. Accessed January 21, 2011.

41) Zhang Q, Huang J, Siwei L (2001) Development of Chinese weather data for building energy calculations. Proc. 4th Inter Conf on Indoor Air Quality, Ventilation and Energy Conservation in Buildings. 1211, Changsha, Hunan.

42) Watanabe T, Urano Y, Hayashi H (1983) Procedures for separating direct and diffuse insolation on a horizontal surface and prediction of insolation on tilted surfaces. Trans Arch Instit Jpn 330, 96-108.

43) IPCC (2007) Climate Change 2007: The physical science basis. Summary for policymakers. Contribution of working group I to the fourth assessment report. The Intergovernmental Panel on Climate Change. http://www. ipcc.ch/SPM2feb07.pdf.

44) Kjellstrom $T$ (2009) Climate change exposures, chronic diseases and mental health in urban populations-a threat to health security, particularly for the poor and disadvantaged. Technical report to the WHO Kobe Centre. Kobe, Japan. World Health Organization, Geneva.

45) Tebaldi C, Knutti R (2007) The use of the multi-model ensemble in probabilistic climate projections. Philos Transact A Math Phys Eng Sci 365, 2053-75. [Medline] [CrossRef]

46) Kjellstrom T, Holmer I, Lemke B (2009) Workplace heat stress, health and productivity - an increasing challenge for low and middle-income countries during climate change. Global Health Action. Special Volume, 46-51. 